
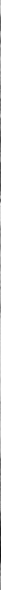

\title{
Identidad e imagen de la ciudad contemporánea: los museos de arte urbano
}

\author{
Laura Luque Rodrigo
}

Resumen: Como indica la Unesco, somos identidad, entre otras cosas, porque somos memoria. Con frecuencia identificamos la identidad con el monumento, con lo antiguo, pero, ¿qué pasa con lo contemporáneo? Es evidente que buena parte de la sociedad, aún en el siglo $\mathrm{XXI}$, no se identifica con el arte de los últimos siglos. A pesar de ello, el arte que está en la calle genera reacciones en la sociedad. Algunos problemas de la ciudad contemporánea han generado soluciones institucionales, ciudadanas y artísticas como la creación de museos. El arte urbano, en muchos casos se ha convertido en el eje vertebrador de estas propuestas que pretenden dotar a las ciudades históricas de una imagen renovada, más actual, de cara al turismo e incluso con el objetivo de crear nuevas identidades para la población local. ¿Tienen realmente este efecto en las ciudades? ¿Consiguen implicar a la ciudadanía? ¿Generan ciudades más resilientes?

Palabras clave: arte urbano, arte público, identidad, museos, ciudad, contemporáneo, arte actual, graffiti

\section{Identity and image of the contemporary city: the urban art museums}

Abstract: As Unesco indicates, we are identity, among other things, because we are memory. We identify the term identity frequently with the monument, with the old heritage, but what about the contemporary? It is evident that a good part of society, even in the 21 st century, does not identify with the art of the last centuries. Despite this, the art that is on the street generates reactions in society. Some problems of the contemporary city have generated institutional, citizen and artistic solutions such as the creation of museums. Street Art, in many cases, has become the backbone of these proposals that aim to provide historic cities with a renewed, more up-to-date image for tourism and even create new identities for the local population. Do they really have this effect in the cities? Do they get to involve citizens? Do they generate more resilient cities?.

Key words: urban art, public art, identity, museums, city, contemporary, current art, graffiti

\section{Introducción: objetivos, metodología y fuentes de la investigación}

Este estudio tiene como objetivo analizar hasta qué punto el arte urbano -sin entrar a valorar si el término es adecuado o no, ya que no es el objetivo de este texto-, crea identidad en la población y, sobre todo, cómo participan de ello los museos que están apareciendo en Europa, dedicados al arte urbano. Se pretende conocer si sus objetivos están relacionados con la población local o con el turismo y si tienen que ver con la identidad de la ciudadanía o con la idea institucional de crear una imagen renovada de las urbes. Para ello, se han empleado desde textos científicos y normativas internacionales, al método de la entrevista. Además, se han usado otros recursos hemerográficos y se han empleado las redes sociales como forma de conocer la opinión de al menos, una parte de la ciudadanía. No se trata de un texto del que se pueda extraer una solución definitiva, sino que abre un debate y aporta datos para ello, tanto cuantitativos como cualitativos.

\section{Imagen e identidad: conceptos}

"La identidad supone un reconocimiento y apropiación de la memoria histórica, del pasado. Un pasado que 
puede ser reconstruido o reinventado, pero que es conocido y apropiado por todos" (Molano, 2007: 84).

El concepto de identidad, asociado a nuestro patrimonio histórico-artístico, ha sido definido por la UNESCO como algo relacionado con la memoria, que comienza a forjarse desde el propio nacimiento y que no solo se asocia a lo inmóvil (González Sáez, s.f.). Si leemos la definición que la RAE (Web) proporciona para identidad, conseguiremos entender en conjunto el concepto: "2. f. Conjunto de rasgos propios de un individuo o de una colectividad que los caracterizan frente a los demás. 3. f. Conciencia que una persona tiene de ser ella misma y distinta a las demás". Por tanto, la identidad es algo que caracteriza a una colectividad frente a las demás, al mismo tiempo que permite a cada individuo ser uno mismo. En definitiva, la identidad es aquello que nos permite ser quienes somos, y nos facilita el reconocernos como parte de un grupo. De ahí que, la UNESCO, insista en el hecho de no asociar la identidad únicamente con lo inmóvil, es decir, que este conjunto de rasgos que nos define como personas y como parte de una sociedad, no viene dado únicamente por nuestro patrimonio monumental, sino que tiene mucho que ver con lo inmaterial: nuestras peculiaridades en el habla, expresiones, gastronomía, fiestas, canciones tradicionales, etc. La globalización, en gran medida, ha homogeneizado nuestras sociedades, haciendo que en parte se pierdan o se igualen cada vez más todas estas costumbres, lo que crea en las comunidades efectos negativos, como el desarraigo. No obstante, aún hoy, quien emigra entiende perfectamente el concepto de identidad, pues cuando en un país extranjero, se escucha una expresión propia de la localidad de origen, los efectos en la persona se hacen patentes tanto en su psique como en su propio organismo. Al fin y al cabo, es la dimensión humana la que da sentido a las ciudades, no tanto sus elementos inertes. En cualquier caso, la identidad es un constructo social por lo que no es inalterable en el tiempo (Agudo Torrico, 1999: 41-42), además, no implica necesariamente homogeneidad, sino que cabe la pluriculturalidad.

Darin (2015: 15), indica que la identidad es una necesidad individual y colectiva, caracterizada por ser afectiva, cognitiva y activa. Hernando Gonzalo (2009), explica cómo la realidad en que vivimos es tan compleja, que los mecanismos que activan la identidad permiten al ser humano sobrevivir sin ser consciente de su pequeñez. Es por ello, porque la identidad implica esas funciones sensibles e inteligibles, así como la eliminación de la ansiedad de la propia existencia, que "cuando se pretende destruir una sociedad, se ataca su cultura, su estilo de vida, su identidad, es decir, se destruye su patrimonio" (Sousa Macias, 2018: 165). De ahí la importancia que la ONU, a través de la UNESCO, otorga a la protección del patrimonio, especialmente en casos de conflictos armados. Nuestra Ley del Patrimonio Histórico Español de 1985, como ya hiciera la de 1933 recoge también la necesidad de proteger el patrimonio, precisamente como manifestación de una identidad cultural.
No obstante, como ya se ha advertido, tendemos a una identidad cada vez más individualizada que implica "un correlativo aumento de la ansiedad. (...) De ahí que quepa esperar que la importancia del Patrimonio se incrementa en proporción directa a la intensificación de los rasgos de individualidad como definidores de la identidad postmoderna" (Hernando Gonzalo, 2009: 97).

Debe tenerse en cuenta además que un individuo a lo largo de su vida puede formar parte de varias comunidades (Romero de Tejada y Picatoste, 2002: 11-23), hecho que cada vez se produce más en nuestras sociedades, por lo que la identidad se vuelve un fenómeno cada vez más complejo a la vez que más necesario, para evitar el desarraigo y promover la cohesión de una sociedad heterogénea y plural, pues aunque la identidad sea una construcción social que se basa en la diferencia, en la alteridad y el contraste cultural (Marcos Arévalo, 2004: 933), debe tender cada vez más al entendimiento del otro, el respeto y la aceptación. La identidad cultural, la pertenencia al grupo, que tan necesaria es, no debe suponer el rechazo a lo diferente, sino todo lo contrario.

Por tanto, debemos preguntarnos no sólo qué papel juega nuestro patrimonio en nuestra sociedad contemporánea en cuanto a la construcción de la identidad a la par que, de valores de respeto e igualdad, sino cómo integrar las manifestaciones artísticas actuales y cómo renovar nuestros museos al respecto de las múltiples subjetividades que conforman nuestras comunidades: "Hay que entender la identidad de forma crítica, distinta de la manera en que tradicionalmente se expresa. Pensarla así permite entenderla como algo cerrado, es decir, la identidad se construye por el Otro, el espacio humano abierto desde aquí permite mostrar que es éste el que recibe al Otro, es lugar de acogida en el que se puede construir identidad" (Aguilar Rocha, 2017: 100).

\section{Ciudad contemporánea e identidad}

Nuestras ciudades están compuestas por una amalgama de acciones humanas sobre el paisaje, que se superponen en el tiempo, eliminando o manteniendo aquellos elementos que, subjetivamente, la colectividad considera susceptibles de olvidar o de conservar. Aquellos elementos que se conservan contraen un valor simbólico que puede venir dado por distintos motivos, ya sean puramente históricoartísticos, religiosos o de cualquier otro tipo. Pueden incluso, perder estos elementos sus valores iniciales, y continuar siendo reconocidos por la comunidad como elementos a conservar por su significación. Estos valores subjetivos, desarrollados ampliamente por Riegl (1903), no hacen sino definir el concepto de identidad. La colectividad convierte algunos de sus elementos en monumentos, mementos, es decir, recuerdos del pasado, otorgándoles nuevos valores que quizá, no tuvieron al ser creados. Pero ¿cómo se integran estos recuerdos en nuestras ciudades? El equipamiento de nuestras urbes se ha ido adaptando, 
junto al urbanismo, a las nuevas necesidades que presenta la sociedad actual, generando al mismo tiempo nuevos conflictos y problemas. En todo esto, se insertan los monumentos, en lo que llamamos centros históricos. Así, dentro de una misma ciudad, podemos distinguir entre ciudades históricas, concepto ampliamente definido y ciudades contemporáneas, peor definida, pero el término aparece tanto en textos científicos como en documentos internacionales como la Carta de Cracovia (2000) (Luque Rodrigo, 2018).

¿Qué sucede por tanto con los símbolos que crean identidad en las ciudades contemporáneas? Podríamos pensar que, en estas zonas, se crean nuevos símbolos, asociados obviamente a la contemporaneidad, pero no siempre sucede así, pues, en definitiva, el ser humano tiende a mirar al pasado y por tanto busca aquellos elementos que contienen el valor de la historia. Es evidente además que, a pesar de estar ya en pleno siglo $\mathrm{XXI}$, el arte contemporáneo, incluso de inicios del siglo $X X$, sigue generando rechazo en buena parte de la población, al menos conscientemente. Es decir, de forma intencionada, pocas personas se declaran identificadas con obras, especialmente plásticas, de un pasado ya no tan reciente. ¿Por qué iba una persona del siglo XXI a identificarse mejor con una obra del barroco que con una de su mismo tiempo? Posiblemente haya una cuestión educacional, y los historiadores del arte y humanistas en general, nos hayamos dedicado más a hacer entender el pasado más remoto, que nuestro propio presente. Sin duda, conocer y entender el pasado es fundamental para entender el presente y poder construir el futuro, pero si el relato termina siglos atrás, en algo se ha fallado (Luque Rodrigo, 2019).

En cualquier caso, esta tendencia disminuye en lo referente a las ciudades y su equipamiento. A fuerza de costumbre, puesto que las calles son ante todo democráticas (todo el mundo las transita) y vividas (no están hechas para ser contempladas como una escultura, sino que en ellas transcurre la vida y las relaciones personales), la arquitectura, el urbanismo, los monumentos urbanos que componen las vías, sí han logrado integrarse mejor en el imaginario colectivo: "en todas las épocas, el patrimonio arquitectónico-urbanístico está presente en la memoria colectiva, aunque sea de manera inconsciente. Referencia necesaria para la construcción de la identidad social e individual" (Venturini, 2004: 159).

Aun así, con bastante frecuencia se producen intensos debates en torno a nuevos edificios que parte de la población considera "demasiado modernos" para un lugar concreto o como no, en torno a todo lo que tienen que ver con el arte urbano, que es el tema que centra este texto. Así, con asiduidad leemos noticias que nos hacen saber que tal comunidad de vecinos se ha levantado en pie de guerra contra cierta obra colocada en sus fachadas, sea espontánea o encargada. ¿Quiere esto decir que el llamado arte urbano no genera identidad?
Antes de nada, debemos dejar claros algunos conceptos relacionados con el arte urbano, que será el término empleado en este texto para referirnos a cualquier tipo de obra situada en la calle, sea espontánea (sin permiso) o por encargo, excepto para los monumentos urbanos, que se definen como aquellos elementos escultóricos colocados por la municipalidad en plazas, parques y calles, para homenajear a algún personaje histórico generalmente, con unas características muy concretas creadas sobre todo a partir del siglo XIX. Si bien no hay consenso en el tema, ni entre los expertos ni entre los propios artistas, con frecuencia se ha venido utilizando arte urbano como un término más amplio que graffiti, puesto que incluye no sólo este tipo de creación artísticas, sino cualquiera que pueda ser realizada en el espacio urbano. Por otro lado, se ha distinguido entre graffiti (vandálico, realizado con espray, que puede ser figurativo, pero que sobre todo son tags, firmas e incluso sticking) y el muralismo, realizado con cualquier otra técnica pictórica, generalmente preparando el muro, figurativo y por encargo. Por otro parte, se viene usando el término arte público, en sustitución de arte urbano, para distinguir aquel que está realizado por encargo y el que no [1].

\section{Arte urbano y ciudadanía}

Talego (2012), explica que las nuevas generaciones de jóvenes deben identificarse con un patrimonio heredado, en el que deben reconocerse, aunque les resulten extraños, por ello, según el autor, el graffiti es un signo que les da sentido de pertenencia en las megalópolis. El autor, define el graffiti como patrimonio inmaterial y va más allá al expresar que "la oficialidad intenta incorporarlos y les ofrece murales y premios. No importa, otros grafiteros vienen detrás reformulando códigos y redefiniendo su singularidad cultural y geográfica" (Talego, 2012: 37).

En tan breve texto encontramos claves importantes, en primer lugar ¿el graffiti y por ende el arte urbano, genera identidad? y ¿en quiénes? Por otro lado, ¿qué tipo de patrimonio es? En respuesta a la primera cuestión, en las siguientes líneas se tratará de mostrar que sí es capaz de crear identidad. En cuanto a la segunda cuestión, tal vez sí debamos entender estas manifestaciones, surgidas con vocación efímera, como una manifestación inmaterial, a pesar de su materialidad, y de su artisticidad en algunos casos, si bien es una cuestión compleja ya que no aparece recogido en la legislación. Por último, el planteamiento de Talego sobre la institucionalización del graffiti es absolutamente pertinente, pues, como se planteará más adelante, al institucionalizar y musealizar estas obras, tal vez estamos provocando que pierdan esa identidad y dejen de fomentar el reconocimiento de los grupos sociales que los crean. El tipo de patrimonio en el que incluyamos al arte urbano será significativo al respecto, puesto que, en un museo dedicado a manifestaciones inmateriales, no se musealiza el producto, sino los objetos que sirven a ello, es decir, no se recrea en el museo una fiesta, sino 
que se muestran materiales u objetos que la conforman, como podrían ser farolillos, ninots, o cabezudos que ya se usaron. Igualmente, si entendemos el graffiti como patrimonio inmaterial, no se musealizarían obras, sino que se contaría su historia, se mostraría material fotográfico o videográfico, y por qué no, botes de espray. Tal vez así, lograrían identificarse con el arte urbano grupos sociales que aún no lo hacen, sin que pierda su razón de ser.

$Y$ es que, son muchos los grupos que aún muestran rechazo por el graffiti, identificándolo con vandalismo, aunque cada vez más la población parece diferenciar entre lo que considera reprobable (las firmas) y lo que considera manifestaciones artísticas (obras figurativas), -quizá la génesis del problema sea, volviendo al inicio de este texto, la supuesta mayor identificación con la figuración barroca que con la abstracción contemporánea-. No obstante, no es cuestión de este trabajo hablar del rechazo, sino de todo lo contrario. Son muchos los ejemplos de lugares que han integrado perfectamente el arte público y el muralismo como parte de sus localidades, los pueblos de Córdoba como La Victoria; Fanzara; el Barrio del Oeste de Salamanca; el Barrio de San Cristóbal de Madrid; Lisboa, etc.

Un ejemplo paradigmático sería el Muro de Berlín, convertido en un auténtico símbolo para la ciudad y que un movimiento ciudadano consiguió salvar cuando se pretendió destruir para construir un hotel en 2013 (Efe, 2013: s.p.). Todo ello institucionalizado, pero con arraigo en la población, puesto que conocen los efectos positivos de estas manifestaciones en sus localidades, tanto por atraer visitantes, como por la experiencia que viven con los artistas, que mejora no sólo la economía de la zona sino la autoestima en el conjunto de la población. Estas iniciativas consiguen lo que se ha venido a llamar por Lerner (2005), acupuntura social. No obstante, en ocasiones al partir estas iniciativas de instituciones alejadas de la sociedad, pueden generar rechazo e incluso gentrificación, como ha sucedido en cierto modo en Málaga.

Algunos ejemplos de cómo el arte urbano genera identidad, los encontramos en los siguientes casos, entre otros:

-En 2016, el mural de Boa Mistura "Porque sueño no estoy loco", pintado cuatro años antes en el marco del Festival Asalto, en Zaragoza, se disponía a ser destruido. Conscientes de que la ciudadanía zaragozana lo consideraba ya un símbolo de la ciudad, se repartieron trozos del muro, ante las largas colas que se formaron (Amatriain, 2016: s.p. / Asalto Web).

-En 2017, el cantante Raphael, contó para el videoclip de Infinitos Bailes, con la presencia del artista urbano Belin. Tanto el cantante como el artista plástico son naturales de Linares (Jaén) y son símbolos de la ciudad para su población, en un caso identificado con una generación adulta, aunque sabiendo captar la atención de los jóvenes y en el otro caso, a la inversa, representante de una generación más joven, pero con la aceptación y el cariño de los más mayores (Linares 28, 2017: s.p). [figura 1]

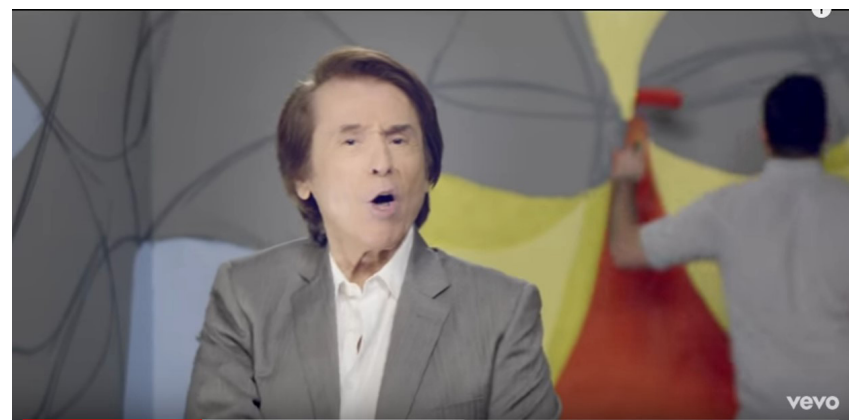

Figura 1.- Fotograma del Videoclip Infinitos Bailes, con Raphael cantando y Belin al fondo pintando. Captura de pantalla de Youtube https://www.youtube.com/watch?v=rF YiH1y0FQ

- En 2019, el cartel oficial de la Semana Santa de Málaga, presentaba un palio pasando ante un muro con un graffiti. El autor, José Antonio Jiménez Muñoz, confesaba que había hecho un cartel arriesgado que se acercaba a la realidad de Málaga, tras crear una gran polémica y el rechazo de una parte de los cofrades malagueños (Escalera, 2019: s.p.). El asunto llegó a tal punto que Diario Sur realizó una encuesta preguntando si gustaba o no el cartel, ganando el No por un $81 \%$, más de 7000 personas participaron en la encuesta (Diario Sur, Web). [figura 2]

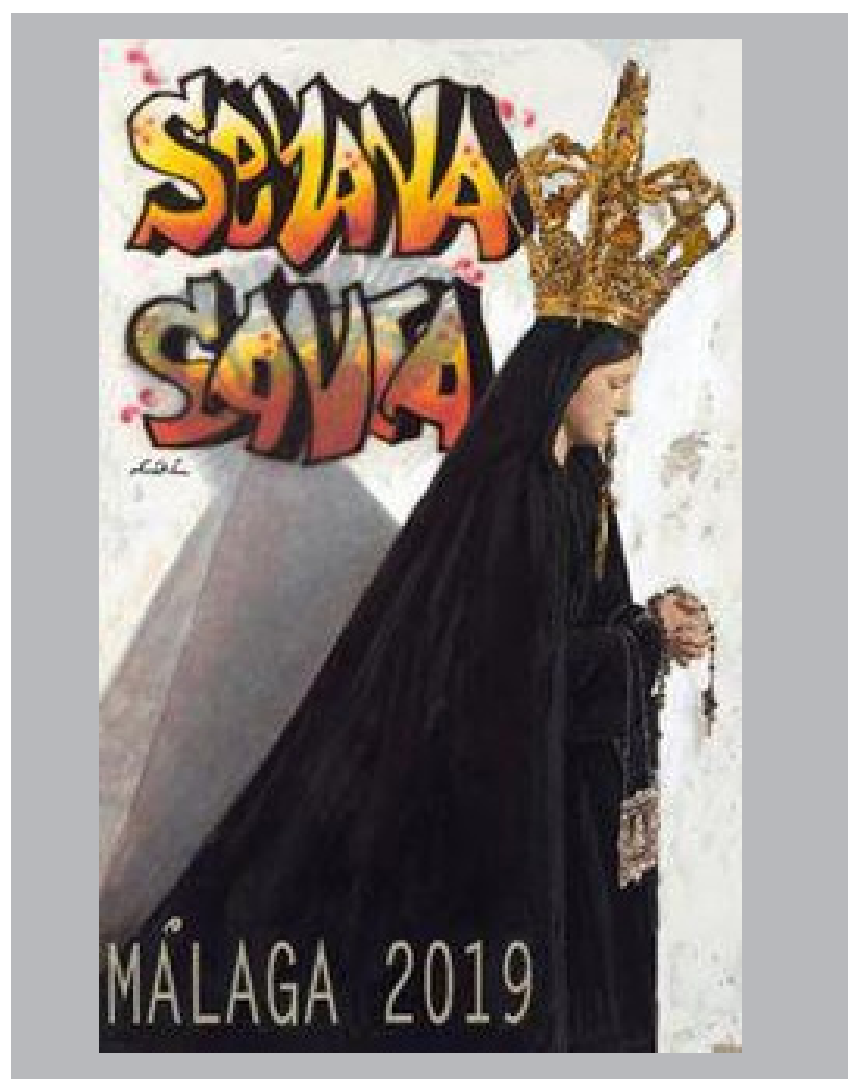

Figura 2.- Cartel de Semana Santa de Málaga 2019. Extraído del Facebook del artista https://www.facebook.com/photo.php?fbid $=813950118959791 \&$ set $=\mathrm{t} .100000891603412 \&$ type $=3 \&$ theater $]$. 
- En 2019, en un lienzo de la muralla de Córdoba, en un lugar emblemático y turístico, aparecieron unas caras, aparentemente talladas, aunque realizadas con escayola y adheridas al muro. Si bien se desconoce aún el autor, rápidamente se asoció al Hombre del Río, una obra que apareció también de forma espontánea en el Guadalquivir a su paso por la ciudad califal, en 2006, obra de Rafael Cornejo y Francisco Marcos. Como sucediera entonces, las autoridades retiraron las caras con diligencia, ante el aplauso de parte de la población, pero también ante la petición de un vasto número de personas, que reclamaban que se quedaran donde habían aparecido (Marzo, 2019: s.p.). [figura 3]

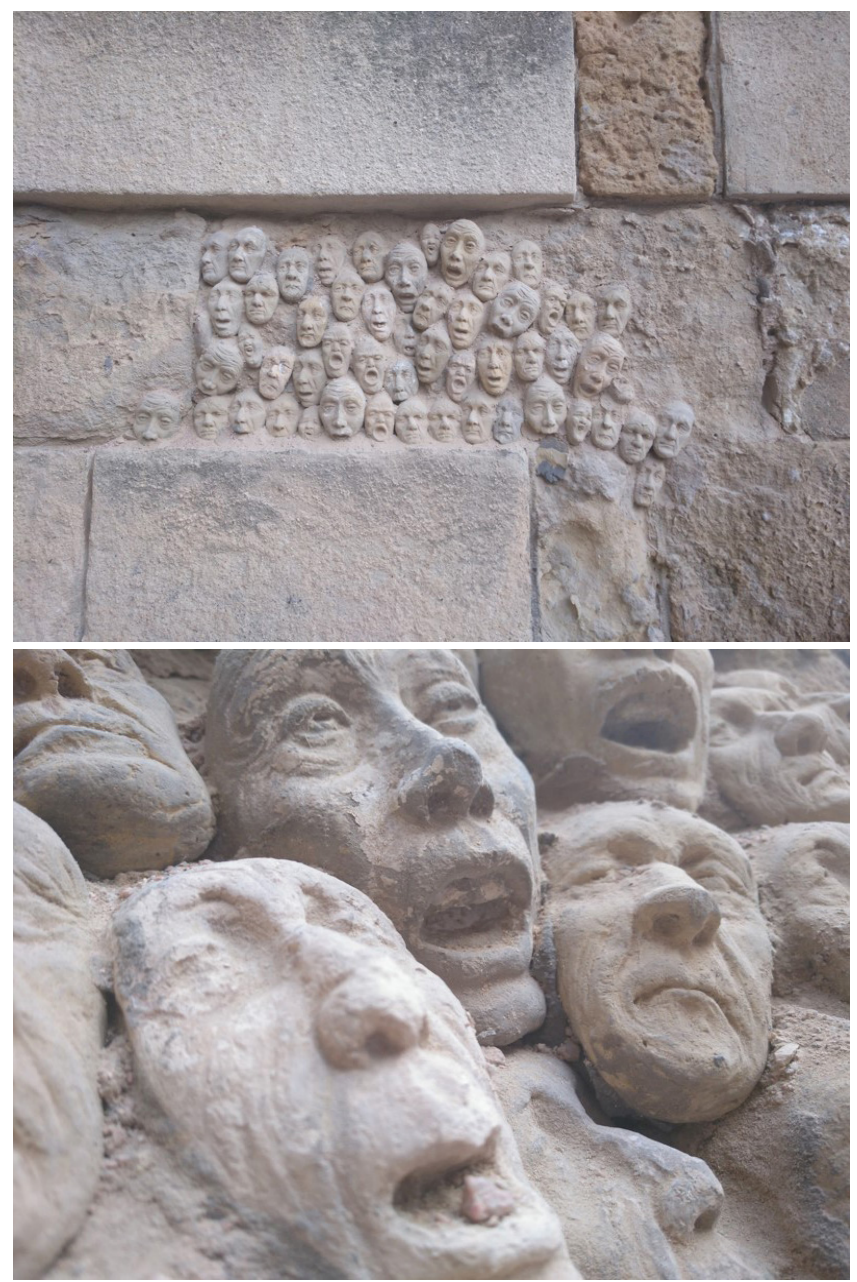

Figura 3.- Caras en la muralla de la Puerta de Almodóvar, Córdoba.

Estos ejemplos han sido elegidos porque representan cuatro formas de mostrar la identidad de un sector de la población con el arte urbano. En el primer caso, el mural de Boa Mistura se convirtió en un objeto fetiche. La ciudad pudo aceptar perder la obra, pero necesitó llevarse un trozo de él, convertirse en pequeños coleccionistas de un pedazo de algo, que quedaba descontextualizado y destruido. De alguna forma, cada persona que se llevó un trocito del muro pasaba a conformar parte de un grupo que, uniéndose, podría recuperar el todo, de manera que ese sentido de pertenencia aparece con respecto al grupo social y al mismo tiempo en relación a la propia ciudad. La apropiación del hábitat no se produce ya únicamente al pasearla y vivirla, sino al poseer parte de uno de sus elementos integradores.

En el segundo caso, el de Raphael y Belin, ambos personajes son símbolos de la ciudad que cuentan con un auténtico fenómeno fan a su alrededor. El cantante es un icono de la ciudad, que lleva su nombre por todo el mundo, lo que le ha valido no sólo el cariño de la localidad, sino contar con un museo a su persona. Por otro lado, la ciudad saca pecho y se enorgullece de ser la cuna de Belin, el graffitero al que antes multaban por actos vandálicos en los muros de Linares, ahora, como artista urbano, lleva su nombre por todo el mundo. Así, dos generaciones se unen en un vídeo y este acto se reproduce en cada concierto del artista, en las pantallas de fondo.

En tercer lugar, el caso del cartel de Semana Santa es paradigmático de una realidad. La ciudad histórica se enfrenta a la ciudad contemporánea, la tradición popular, en este caso concreto de Málaga, se ve cara a cara con la cultura institucional, en un duelo entre la identidad y la imagen. La fiesta de la Semana Santa, aunque multitudinariamente turística en ciudades como Sevilla o Málaga, sigue teniendo una gran raigambre popular, la ciudad entera se identifica con ella, no sólo por fervor religioso, sino porque es un icono, un acto social de encuentros y reencuentros, una catarsis donde vivir la calle. Sin embargo, en el caso de Málaga encontramos el contrapunto de forma muy clara, aunque no es la única ciudad española y del mundo que trabaja en estas lides, renovar la imagen de la ciudad mediante lo contemporáneo. Pero ¿se identifica la población con esa nueva imagen o es algo de cara al exterior?

Son muchas las voces críticas, incluso dentro del mundo de la cultura, por los efectos negativos que conlleva todo esto, gentrificación, turistificación, elitización del centro histórico. Así, Rogelio López Cuenca junto a Elo Vega, crearon en 2017 la iniciativa Málaga 2026, arropados por la Casa Invisible y el MNCARS, que supone una crítica al equipamiento cultural, en lo que aparece también el arte urbano institucionalizado, y que invita a pensar en otra ciudad (Málaga 2026, web). Podríamos pensar que de alguna forma, el cartel legitima estas prácticas culturales alejadas de la población local las asume ya como propias de la ciudad. El autor, Jiménez Muñoz, en diversas entrevistas, señalaba cómo pretendía acercar la Semana Santa a la realidad de la ciudad, y es cierto que los tronos pasan ante un graffiti. Sin embargo, se creó cierta polémica puesto que en los foros cofrades hubo rechazo.

Pero ¿Por qué se produce dicho rechazo? ¿Es porque la gente se opone a este modelo de ciudad? Quizá, más probablemente, sea por la eterna lucha entre tradición y modernidad. Aún parece que ambos mundos no se pueden mezclar, que durante las fiestas tradicionales 
debemos volvernos barrocos, para ser contemporáneos ya está "La Noche en Blanco", como si tuviéramos distintas personalidades a lo Dr. Jekyll y Mr. Hyde. En cualquier caso, el autor, a su vez, es muestra de otra parte de la población, aquella que ya integra ambos parámetros, que se identifica tanto con una cosa como con la otra.

Por último, el 21 de junio de 2019, aparecieron en Córdoba, más de cincuenta caras de escayola, con pigmento que simulaba el color del sillar del muro al que se adhirieron con un adhesivo bicomponente [2], a parte de la muralla situada junto a la Puerta de Almodóvar. El día 24 ya estaban siendo retiradas por el Ayuntamiento, sin embargo, durante el fin de semana que perduraron, se generó un intenso debate en las calles de la ciudad $y$ en redes sociales, donde mucha gente mostraba su indignación y rechazo, pero otro grupo de igual envergadura pedía que se dejaran, pues "les gustaba", a pesar de tratarse de un delito contra el patrimonio y el posible daño causado al muro. La noticia salió en los telediarios del día y el fenómeno fue tal que, durante esos tres días, hubo colas para realizar una fotografía a la obra e incluso, hubo personas que extrajeron algunas de las caras, arrancándolas sin cuidado.

Este acontecimiento nos deja varias lecturas. Por un lado, cómo la ciudadanía, o parte de ella, atendiendo simplemente a un criterio de gusto personal, puede identificarse rápidamente con el arte urbano, asimilado como arte actual, aunque sea ilegal. Por otro lado, la experiencia anterior del Hombre del Río, nos enseña cómo un movimiento ciudadano puede generar que una obra vandálica sobre un monumento logre su legitimidad y sea conservada por las instituciones. Además, este hecho abre el debate de la propiedad. ¿Puede la gente arrancar la obra y llevarse parte de ella sin más? ¿No sería también esto un delito? $\mathrm{O}$ ¿nos encontramos ante el hecho de que por ser un acto vandálico todo vale?
Leer las conversaciones producidas en Facebook sobre este tema, es interesante, pues había quien pedía que se quedaran y si alguien le respondía que era vandalismo, la contra respuesta era: "vale, pero me gusta, que lo dejen". El propio Diario Córdoba, en su entrada a esta red social donde copiaba el enlace a la noticia, escribía "¿Arte o vandalismo?", animando así el debate. Los alegatos en contra se centraban en el daño al monumento o incluso se dudaba de su artisticidad ("arte, dudo. Vandalismo puro"), en cuanto a los alegatos a favor, se reproducen algunos a continuación: "Para mí es arte, arte callejero del bueno. Porque me impacta, me llama la atención, me provoca y para colmo lo he sentido integrado en ese todo (...)". "Si todo lo vandálico fuera así, estaríamos llenos de obras de arte". "Un artista sin ninguna duda, sería perfecto que lo dejaran me encanta y me parece una manera de atraer más turismo un aplauso para el artista" [3] [figura 4]

Estos comentarios dan buena cuenta de distintas ideas: la relación del gusto con el aspecto sensible y la aceptación de la obra en gran medida por su integración con el entorno (una obra que no se integra con el entorno, sea por encargo o espontánea, suele producir rechazo, de ahí el éxito del arte relacional); la supuesta necesidad, en una ciudad como Córdoba, de atraer más turismo a través de más obras de arte (que generó debate en sí con respuestas como: "la muralla en sí ya es arte, el turista que quiera ver arte que se vaya al museo Julio Romero (...)" o "Córdoba ya tiene demasiado turismo, como para dejar este acto vandálico como atracción") - se genera un debate similar al malagueño-. En un lugar intermedio: quienes lo reconocían como arte, pero situado en el lugar incorrecto. Se debe señalar también un comentario que decía "Prefiero esto, antes que los grafitis", es decir, se acepta el relieve, pero se rechaza el graffiti, siendo en todo caso el mismo tipo de expresión artística, variando tan sólo los materiales, quizá porque se asocie con más frecuencia a lo vandálico el empleo de la pintura en aerosol.
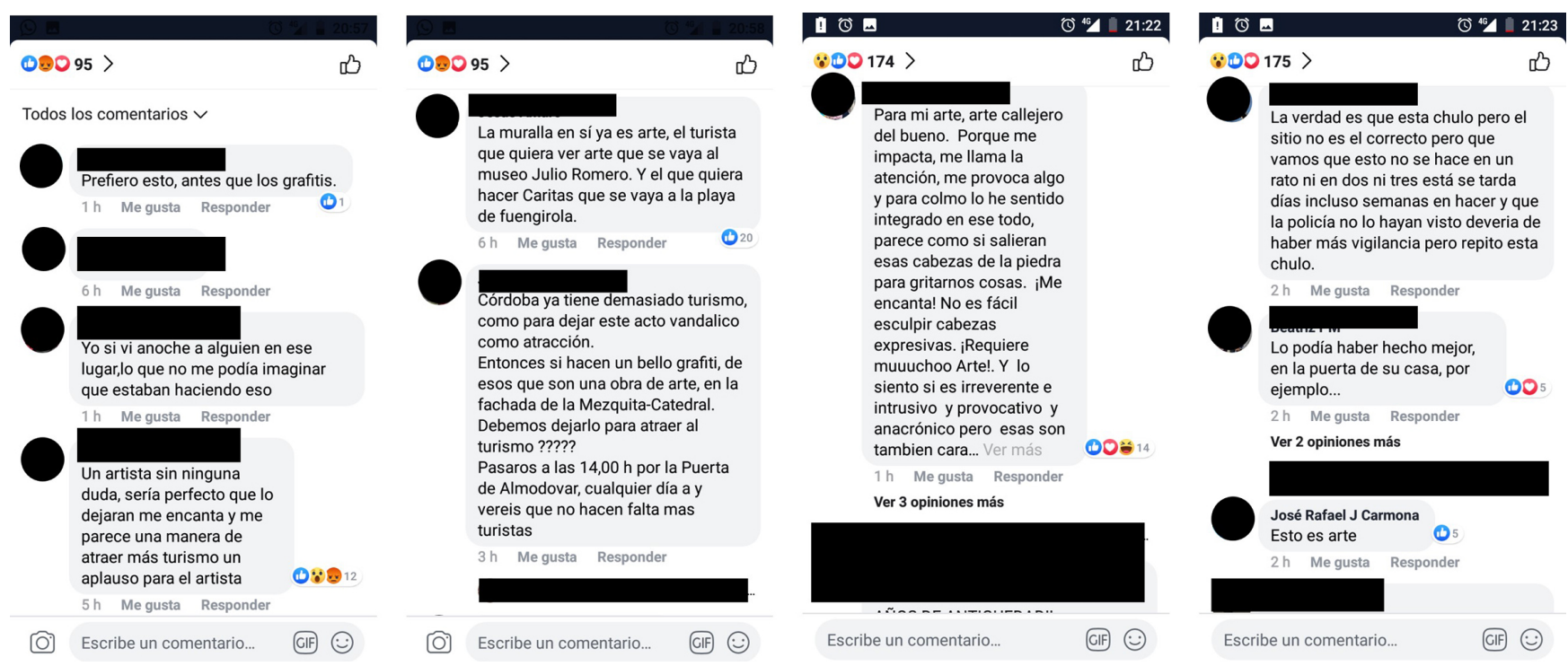

Figura 4.- Captura de pantalla del Facebook de Cordópolis y Diario Córdoba, en la entrada a la noticia sobre las caras. 
En definitiva, con estos ejemplos se puede comprobar cómo el arte urbano puede generar identidad a través de distintos procesos y medios, y dar como resultado la conservación o no de las obras, pero hay que reconocer que sí generan sentimiento de cohesión social a través del reconocimiento, aunque también el debate y muchas críticas.

\section{Museos de arte urbano ¿para quién y para qué?}

“El museo es una institución sin fines lucrativos, permanente, al servicio de la sociedad y de su desarrollo, abierta al público, que adquiere, conserva, investiga, comunica y expone el patrimonio material e inmaterial de la humanidad y su medio ambiente con fines de educación, estudio y recreo" (ICOM Web). Esta definición, ahora en revisión por el ICOM [4], contiene las funciones principales de los museos, por un lado, es fundamental su labor de conservación y por otro de comunicación. No obstante, los museos son algo más, son entidades capaces de generar identidad (Sierra Salcedo, 2016: 391), de hecho, los primeros surgen durante los nacionalismos, en busca precisamente de crear una identidad nacional, diferenciada del resto. El museo legitima, además, prácticas culturales "que en muchos casos acaban siendo desvirtuadas, simplificadas o mitificadas en exceso" (Camps, 2011: 172). ¿Estarían los museos de arte urbano, que están surgiendo en Europa en los últimos años, legitimando esta práctica artística, a la par que la desvirtúa y mitifica?

Lo cierto es que los museos, por muchos llamados "cementerios de obras de arte", no hacen sino recoger obras que se encuentran descontextualizadas, pensemos en las palas de altar, en las pinturas murales del románico en el Museo de Cataluña, y en otros tantos ejemplos. Las obras musealizadas pierden su uso original. Por lo tanto, cabría preguntarse ¿puede un museo contener arte urbano? ¿Si no está en las calles puede llamarse urbano? En cualquier caso, parece que pierden su significación original, al no estar en la calle dejan de ser obras democráticas -que serán contempladas por todo tipo de público, vaya o no a museos-, especialmente si se cobra entrada.

Al margen de esta cuestión, la realidad es que en los últimos años han surgido en ciudades como Berlín o Ámsterdam, entre otras muchas, museos de arte urbano que están logrando, al menos, éxito mediático. ¿Para quién o para qué surgen estos museos? Lo cierto es que la creación de estos espacios está vinculada a esa búsqueda del Efecto Guggenheim, crear espacios que generen una nueva imagen de las ciudades, más contemporánea, nuevos focos turísticos, la espectacularidad, a costa, en muchos casos, de la homogeneización de las ciudades y su consiguiente pérdida de identidad, pues el skyline de todas acaba siendo muy similar. No hay más que ver dónde se sitúa el MoCo, en el Museumplein de Ámsterdam, entre el Rijksmuseum y el Museo Van Gogh, es decir, en pleno núcleo turístico y museal. ¿Es esto una elitización del arte urbano o una provocación? [figura5]

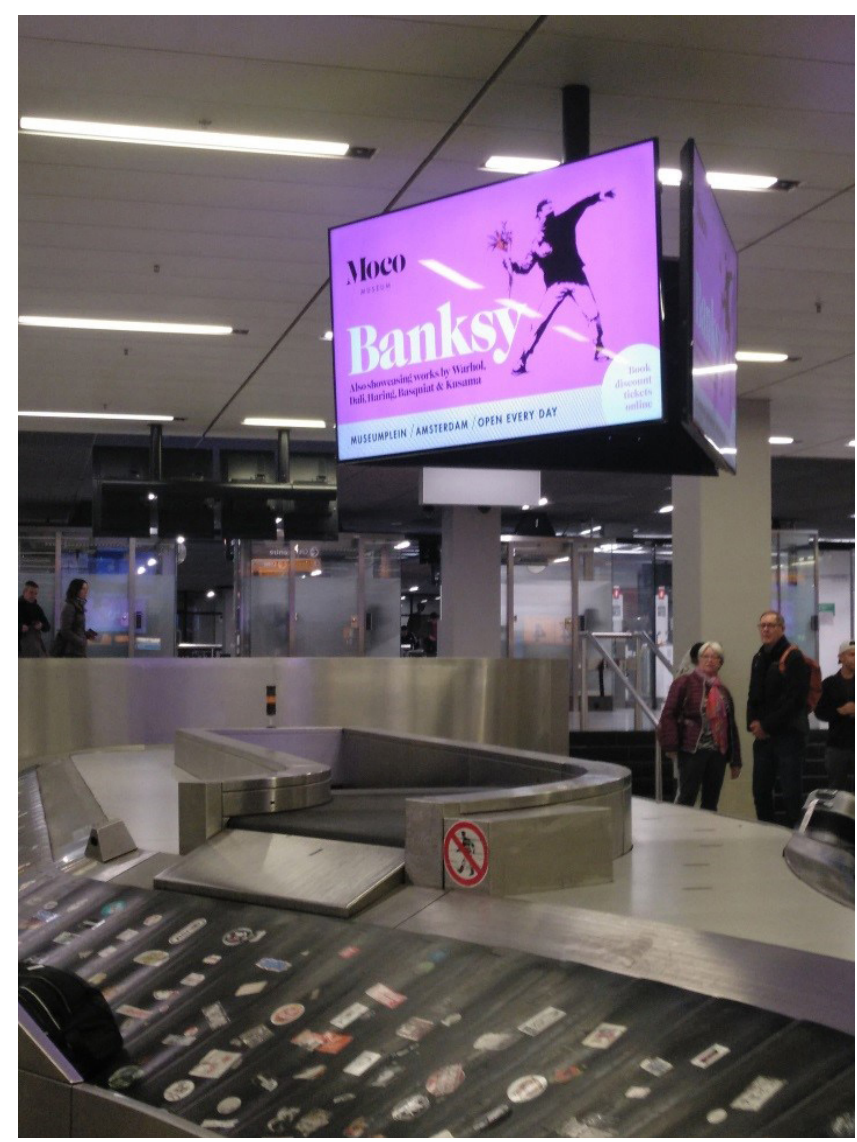

Figura 5.- Publicidad sobre el MoCo a la llegada del Aeropuerto de Ámsterdam. Enero de 2019.

¿Están por tanto estos museos creando nuevas identidades en las poblaciones? ¿O sólo crean imagen? Hay que valorar "en qué medida el desarrollo de una oferta patrimonial va a contribuir a mejorar la calidad de vida de la población" (Miró i Alaix, 1997: 34) y preguntarse ¿de quién es el patrimonio? Para Tunbridge (2006: 93) la respuesta suele ser "una cuestión de identidad cultural". Pero, puesto que "la política de patrimonio tiene impactos económicos directos (creación de empleos, generación de ingresos) e inducidos (desarrollo de sectores vinculados a la industria cultural, tales como la producción audiovisual)" (Lisocka-] aegermann, 2004: 13), puede conllevar la invención de patrimonio e identidades.

Se ha enviado a varios de estos museos una encuesta a través de Google Formularios, a la que han respondido tan sólo dos: Street Art Museum [5] Amsterdam y el MAU de Turín. Se les ha preguntado si ¿creen que su museo aporta a la ciudad algo nuevo con lo que identificarse?, a lo que ambos han respondido que sí; ¿creen que los habitantes de su ciudad sienten como propio el museo? Con un 100\% de respuestas afirmativas; ¿el museo recibe más visitas de extranjeroso delocales? Ambos responden que extranjeros, lo que claramente contrasta con la respuesta anterior, pues si los habitantes se identifican con el museo y lo sienten como propio, sería lógico que la programación estuviese pensada más para un público local que extranjero y así se dejase notar en las cifras. Por ello, la siguiente pregunta era si hacen actividades para atraer a la población local, siendo 
la respuesta también afirmativa; a la pregunta ¿cree que su museo contribuye a mejorar la oferta cultural de su ciudad? También ambos respondieron que sí; ¿cree que su museo contribuye a modernizar la imagen de su ciudad al mostrarla más actual? 100\% sí; en la pregunta ¿cree que la gente se identifica con el arte urbano? Ambos creen que sí, que no prefieren el arte tradicional, si bien esta pregunta contrasta con las cifras de visitas a museos dedicados a otras etapas artísticas, por ejemplo, en Ámsterdam el MoCo recibe 404.404 visitas frente a los más de dos millones del Rijksmuseum o el Museo Van Gogh (Ámsterdam Web).

Se les preguntó también si ¿creen que puede llamarse urbano a obras de arte que se muestran dentro de un lugar cerrado? Donde se pierde la unanimidad. Esta pregunta va ligada a la siguiente ¿cree que el arte urbano, especialmente el graffiti, queda descontextualizado al sacarlo de las calles? Sin embargo, aquí el 100\% respondió que sí; por último, ¿cree que los museos de arte urbano deben estar conectados con los demás monumentos y museos de la ciudad o es preferible que se emplacen en lugares distintos para llevar la cultura a más rincones de la ciudad? La respuesta a esta pregunta en ningún caso fue afirmativa, en un caso se respondió que es indiferente y en otro que sí deben estar en un lugar diferenciado.

En cualquier caso, debe tenerse en cuenta que ambas instituciones se corresponden con los llamados "museos al aire libre", ninguno de los museos "cerrados" ha querido responder. Ambos museos están insertos en un entorno donde existía el arte urbano e implican a la gente del barrio. El Street Art Museum, señala que trabajan en documentar la escena del graffiti y destinarán actividades a la población local, al mismo tiempo que a través de su director, Peter Coolen, que trabaja el graffiti desde hace tres décadas, tienen aceptación, según señalan, dentro de la propia comunidad artística. Apuntan además que una de las formas de llevar el arte urbano al museo, pasa por contextos industriales, pues el muro blanco no funciona bien. Además, su ubicación se aleja del núcleo turístico, lo que permite dispersar la congregación de turistas.

\section{Conclusiones}

En definitiva, debemos pensar que ciertamente el "arte urbano", que genera identidad, es susceptible de ser estudiado como otras manifestaciones artísticas, en su contexto; sin embargo, su exposición es distinta, pues si pierde su función, podríamos provocar su muerte. Además, cuando se trate de artistas vivos, sin duda habría que contar con su opinión. Por otro lado, debe tenerse en cuenta que existen museos de arte urbano de distinto tipo en su propia génesis. Así, pueden estar creados por los propios artistas o comunidades o por instituciones, en cada caso funcionarán de una forma u otra y se dirigirán a un público u otro. No es lo mismo exhibir obras de artistas creadas para otro tipo de exposición, que dejar los muros para que sean intervenidos y mostrar obras arrancas dentro, sin permiso de los autores; esto no debería pasar por alto a los visitantes y la población.

Tal vez, se debería tomar nota de la exposición Arte en la Calle Madrid 2000 - 2018 (Conde Duque, Web), donde no se muestran obras, sino información sobre ellas, de manera que permite conocerlas mejor e invita a visitarlas en las calles. Otra opción sería mostrar el arte urbano, como ya se propuso anteriormente, de la manera que se construyen los museos etnológicos, manteniendo así viva la tradición, "el ser entorno protector de los objetos como trasuntos de un patrimonio vivo, sucesión de un 'continuum" (Zubiaur Carreño, 1999: 287). Según Pérez Simón (2015: 70), la identificación, hoy día, se da "cuando las comunidades empiezan a defender el patrimonio propio", es decir, que la ciudadanía se identificará con el arte urbano cuando comience a defenderlo, lo que ya ha empezado a suceder como se ha mostrado, pero no tanto por su inclusión en los circuitos artísticos. También Castaneira (2017: 1206) defiende la necesidad de la participación, pues al fin y al cabo es la sociedad "la causante de otorgar valor al patrimonio. De otra manera, esos vestigios culturales sólo serían restos carentes de historia y simbolismo".

Por todo ello, "no existiría identidad cultural sin memoria" (Cepeda Ortega, 2018: 254), es decir, es la sociedad quien debe considerar, en este caso, al arte urbano, como parte de su patrimonio, y será labor de los expertos el hacerlo entendible y activar la experiencia patrimonial (Muriel, 2018: 96). ¿Cómo realizar esa activación? Desde luego, posiblemente no pase por crear museos que buscan la espectacularidad del propio inmueble, orientado a los visitantes y mostrando obras arrancadas o que no forman parte del arte urbano como tal. Quizá la clave sea orientarse más a mostrar los procesos, la historia, los artistas locales e invitar a visitar los muros. En cualquier caso, parece un fenómeno imparable, pero no en todas las ciudades tiene que haber un museo de arte urbano, abierto o cerrado, como no tienen por qué haber una noria como la de Londres en todos los skylines. Los profesionales de la historia del arte y la conservación del patrimonio, así como otras disciplinas como la antropología o el derecho, deben trabajar como intermediarios, de manera que tanto los artistas como las sociedades sientan como propias las iniciativas relacionadas con el arte urbano, teniendo en cuenta que si la creación parte de la institución, se pierde buena parte de la propia identidad intrínseca del arte urbano y deberemos Ilamarlo arte público o muralismo.

Volviendo a las funciones del museo, debemos preguntarnos qué conservar con respecto al arte urbano ¿las obras o los procesos vivos? Si optamos por lo primero, redefiniremos la propia creación urbana arrebatándole su sentido inicial, sin embargo, optar por lo segundo podría no sólo mejorar la relación entre institución y artistas, sino también cómo comunicar esto a la sociedad, para que pueda generarse un sentimiento de pertenencia real y no impostado. 


\section{Notas}

[1]. Sobre este tema, leer el texto de Elena García Gayo en este mismo monográfico.

[2]. El día 24, durante la retirada, se pudieron comprobar dichos datos en conversaciones con la restauradora, el arquitecto municipal y el arquitecto de la Junta de Andalucía.

[3]. Es una pequeña selección de comentarios extraídos de las entradas de Facebook del Diario Córdoba sobre la noticia, entre el 22 y el 24 de junio.

[4]. En Kioto en septiembre de 2019, durante la XXV Conferencia General del ICOM, se iba a generar la nueva definición, si bien ha quedado aplazado.

[5]. El nombre oficial será anunciado dentro de poco.

\section{Bibliografía}

AGUILAR ROCHA, I.S. (2017). "La ciudad contemporánea: identidad y patrimonio". En $V$ Congreso Internacional Cidades Creativas, Janeiro: Facultade de Letras da Universidade do Porto, 97-105.

AMATRIAIN, A. (2016). "Llévate un pedazo del mural de Boa Mistura", Heraldo de Zaragoza [18 de febrero de 2016], s.p. Disponible en https://www.heraldo.es/noticias/aragon/ zaragoza/2016/02/18/festival-asalto-reparte-pedazos-del-muralboa-mistura-entre-todos-los-zaragozanos-771725-2261126.html [Consulta: 23/07/2019].

AMSTERDAM WEB. https://amsterdam.org/en/facts-and-figures. php [Consulta: 23/07/2019].

ASALTO. http://www.festivalasalto.com/adios-al-mural-de-boamistura/ [Consulta: 23/07/2019].

CAMPS, R.R. (2011). "El museo como instrumento de legitimación en la construcción de identidades", Educación Artística Revista de Investigación, 2: 170-174.

CASTANEIRA, E. (2017). "Cidade: construção identitária". En V Congreso Internacional Cidades Creativas, Janeiro: Facultade de Letras da Universidade do Porto, 1191-1208.

CEPEDA ORTEGA, J. (2018). “Una aproximación al concepto de identidad cultural a partir de experiencias: el patrimonio y la educación", Tabanque, 31:244-262.

CONDE DUQUE WEB. https://www.condeduquemadrid.es/ actividades/exposicion-arte-en-la-calle-madrid-2000-2018 [Consulta: 24/07/2019].

DARIN, S.B. (2015). “Conservación del Patrimonio y la Identidad en la Sociedad del Conocimiento: el rol de la Universidad", Revista Publicando, 2: 3-24.
DIARIO SUR WEB. https://www.youtube.com/watch?v=rF YiH1y0FQ [Consulta: 24/07/2019].

EFE. (2013). "Las protestas masivas evitan que un constructor alemán tire partes del muro de Berlín", $A B C$ [4 de marzo de 2013], s.p. Disponible en https://www.abc.es/internacional/20130304/abciconstructor-muro-berlin-renuncia-protestas-201303040930. html [Consulta: 24/07/2019].

ESCALERA, A. (2019). "No he hecho el cartel para que guste a todo el mundo; he huido de lo manido", Diario Sur [12 de enero de 2019], s.p. Disponible en: https://www.diariosur.es/semanasanta/cartel-guste-mundo-20190112233154-nt.html [Consulta: 23/07/2019].

GONZÁLEZ SÁEZ, O.J. (s.f.). "La formación de la identidad cultural. Una mirada desde una escuela asociada a la UNESCO", http://www.unesco.org/new/fileadmin/MULTIMEDIA/FIELD/ Havana/pdf/laformaciondelaidentidadcultura.pdf [Consulta: 22/07/2019].

HERNANDO GONZALO, A. (2009). "'"El Patrimonio: entre la memoria y la identidad de la Modernidad", PH 70: 88-97.

ICOM Web. https://icom.museum/es/actividades/normas-ydirectrices/definicion-del-museo/[Consulta: 24/07/2019].

LERNER, J. (2005). Acupuntura Urbana. Barcelona: Institut d'Arquitectura Avançada de Catalunya.

LINARES 28. (2017). "Raphael y Belin se unen gracias a los 'Infinitos Bailes"', Linares 28 [3 de junio de 2017], s.p. Disponible en https:// www.linares28.es/2017/06/03/raphael-belin-se-unen-graciaslos-infinitos-bailes/ [Consulta: 22/07/2019].

LISOCKA-]AEGERMANN, B. (2004). "Patrimonio cultural, identidad y territorio: problemas de investigación", Espacio y desarrollo, 16: 9-25.

LUQUE RODRIGO, L. (2018). "La ciudad contemporánea: problemas y tendencias. Perspectivas institucionales, sociales y artísticas", SÉMATA, Ciencias Sociais e Humanidades, 30: 377-398.

LUQUE RODRIGO, L. (2019). "Reflexiones sobre arte urbano y educación: de lo académico a lo colectivo", Mural Street Art Conservation, 8: 7-9. Observatorio de Arte Urbano

MÁLAGA 2026. http://malaga2026.net/[Consulta: 24/07/2019].

MARCOS ARÉVALO, J. (2004). "La tradición, el patrimonio y la identidad", Revista de estudios extremeños, 3: 925-956.

MARZO, I. (2019). "Buscan al autor de las caras de la Puerta de Almodóvar", Diario Córdoba [22 de junio de 2016]: s.p. Disponible en https:/www.diariocordoba.com/noticias/cordobalocal/ buscan-autor-caras-puerta-almodovar 1308724.html [Consulta: 22/07/2019].

MIRÓ I ALAIX, M. (1997). "Interpretación, identidad y territorio. Una reflexión sobre el uso social del patrimonio", $P H$ 18: 33-37. 
MOLANO, O.L. (2007) "Identidad cultural un concepto que evoluciona", Opera, 7: 69-84.

MURIEL, D. (2018). Identidady patrimonio. Manual (desdela sociología) para entendery gestionar el patrimonio cultural. S.C.: Lulú.

PÉREZ SIMÓN, S. (2015). “Patrimonio e identidad: una exploración de las múltiples caras del patrimonio". En Antropología e Identidad. Reflexiones interdisciplinarias sobre los procesos de construcción identitaria en el siglo XXI. Valladolid: Fundación para la Investigación y Formación en Interculturalidad y Educación para el Desarrollo: 6576.

RIEGL, A. (1903). El culto moderno a los monumentos: caracteres y origen. Ed. Madrid:Visor, 1987.

ROMERO DE TEJADA Y PICATOSTE, P. (2002). "Identidad cultural y museos. Una visión comparada", Museo, 6: 11-23.

SIERRA SALCEDO, I.A. (2016). "Museos e identidad: espacios en juego". En Deconstruir la alteridad desde la didáctica de las ciencias sociales: educar para una ciudadanía global. Las Palmas de Gran Canaria: Universidad de Las Palmas de Gran Canaria: 391-397.

SOUSA MACÍAS, C. (2018). “¿Se destruye patrimonio o identidad cultural?", $P H$ 93: 165-166.

TALEGO, F. (2012). "Grafitis: huellas de un patrimonio inmaterial urbano", mus-A Revista de los museos de Andalucía, 13: 36-37.

TORRICO AGUDO, J. (1999). "Cultura, patrimonio etnológico e identidad", PH 29: 36-45.

TUNBRIDGE, J.E. (2006). “¿De quién es el patrimonio? Conflicto, cultura e identidad", $P H$ 58: 93.

RAE. https://dle.rae.es/srv/search?m=30\&w=identidad [Consulta: 22/07/2019].

ZUBIAUR CARREÑO, F.J. (1999). “El Museo al servicio de la memoria e identidad colectivas", Cuadernos de etnología y etnografía de Navarra, 73: $281-288$.

VENTURINI, E.J. (2004). “Centros urbanos, patrimonio e identidad ciudadana en el mundo de la globalización", Estudios, 15: 157-168.

\section{Autor/es}

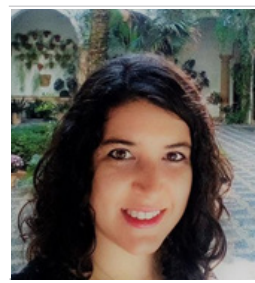

\section{Laura Luque Rodrigo}

Universidad de Jaén

Iluque@ujaen.es

Doctora en Historia del Arte por la Universidad de Jaén, es actualmente profesora en la misma universidad. Ha trabajado en inventarios artísticos institucionales. Ha participado en diversos proyectos relacionados con el arte contemporáneo, publicado múltiples artículos en revistas científicas y capítulos de libro; catálogos de exposiciones y libros. Ha participado en una treintena de congresos nacionales e internacionales, e impartido conferencias en diversas instituciones nacionales e internacionales. Realizó una estancia de investigación en la Pontificia Università Gregoriana de Roma y una estancia docente en la Universidad de Siena; recibió un premio de emprendimiento. Es miembro del comité científico de varias revistas y es miembro del Grupo de Arte Urbano ligado al GEIIC. Pertenece al grupo Arquitecto Vandelvira (HUM 573). Además ha coordinado una veintena de actividades divulgativas, como cursos, ciclos de conferencias, mesas redondas, etc 